\title{
JENIS DAN DESKRIPSI KELELAWAR PEMAKAN BUAH DI SEKITAR KAWASAN HUTAN DATARAN RENDAH PANTAI UTARA MANOKWARI
}

\section{(Type and Description of Fruit Bath Around the Low Land Forest Area of North Coast of Manokwari)}

\author{
Ismael Sawor ${ }^{1}$ dan Hermanus Warmetan ${ }^{1 凶}$ \\ Jurusan Kehutanan, Fakultas Kehutanan Universitas Papua Manokwari, Papua Barat, \\ 98314. Tlp/Fax: +62986211065. \\ ${ }^{\square}$ Penulis Korespondensi: Email: h_warmetan@yahoo.co.id \\ Diterima: 10 Agust 2018| Disetujui: 02 Sept 2018
}

\begin{abstract}
Abstrak
Tujuan dari penelitian ini yaitu mengkaji jenis kelelawar pada kawasan hutan dataran rendah pantai utara Kabupaten Manokwari. Metode yang digunakan dalam penelitian ini adalah metode deskriptif dengan teknik jelajah. Hasil penelitian menunjukkan bahwa terdapat tiga jenis kelelawar pemakan buah yang ditemukan yaitu: Nyctimene albiventer, Rousettus amplexicaudatus, dan Macroglossus minimus yang semunya berasal dari satu famili yakni pteropodidae. Dari ketiga jenis kelelawar yang di jumpai, Rousettus amplexicaudatus merupakan jenis dengan jumlah individu terbanyak di bandingkan kedua jenis lainnya. Tingginya individu jenis ini di duga karena memiliki populasi yang sangat besar karena adaptasi yang cukup baik terhadap lingkungan.

Kata kunci: Kelelawar buah, famili pteropodidae, hutan dataran rendah, karakteristik morfologi.

Abstract

This study is willing to describe types of bath that is found around low land forest area of north coast of Manokwari. The study used a descriptive method through field observation along a tracking line. The result pointed out that three species of fruit baths have been identified namely: Nyctimene albiventer, Rouset tus amplexicaudatus, and Macroglossus minimus which were emanated from pteropodidae family. From these three species, Rousettus amplexicaudatus was dominant in the area compared to those two others. The dominance was likely caused by its population and preferred habitat for this species to live as well as easy to adapt with the surrounding environment.
\end{abstract}

Keywords: Fruit bath, pteropodidae family, low land forest, morphological characteristic.

\section{PENDAHULUAN}

Papua merupakan bagian barat pulau besar Nugini yang memiliki luas wilayah $416.129 \mathrm{~km}^{2}$ dan mendukung hutan hujan rimba tropis terluas yang masih ada di Asia Pasifik. Di Papua, mamalia moderen meliputi monotremata terbesar di dunia, lebih banyak marsupial arboreal dibandingkan di tempat lainnya, dan salah satu tempat yang memiliki jenis kelelawar buah dunia lama yang terbanyak (Kartikasari dkk. 2012). Kelelawar merupakan satu jenis mamalia yang 
dikenal luas oleh masyarakat Indonesia. Sebenarnya, ada dua tipe kelelawar yang ditemukan di Indonesia yaitu kelelawar pemakan buah dan kelelawar pemakan serangga. Apabilah dilihat dari aspek ekologis, kedua tipe kelelawar tersebut memiliki peran penting dalam mengatur keseimbangan ekosistem. Kelelawar pemakan buah berperan dalam memencarkan biji dari buah-buahan yang dimakan, sedangkan kelelawar pemakan serangga berperan dalam mengatur keseimbangan serangga pengganggu tanaman (Santosa dkk. 2008).

Di Papua kelelawar pemakan buah dari suku pteropodidae sangat beragam, yang diwakili oleh kalong pemakan buah berbadan besar (Pteropus), Nyap (Rousettus) pemakan buah berukuran kecil hingga sedang dan kelelawar buah pungun gundul (Dopsonia), serta paniki (Nyctimene dan Paranytimene) yang memakan buah kecil, Serangga, dan pemakan nectar buanga (Syconycteris dan Macroglossus) (Kartikasari dkk. 2012).

Flannery (1995) juga melaporkan bahwa di daerah kepala burung Manokwari terdapat beberapa jenis kelelawar yang menyebar di beberapa wilayah antara lain Pegunungan Arfak, Pulau Mansinam, Saukorem dan sepanjang Pantai Utara Manokwari. Kampung Asai adalah salah satu kampung yang terletak di Distrik Manokwari Utara, Kabupaten Manokwari, Provinsi Papua Barat, yang mana kampung tersebut juga termasuk dalam wilayah penyebaran kelelawar di daerah kepala burung Pulau Papua. Tujuan dari penelitian ini adalah untuk mengetahui jenis-jenis kelelawar yang berada di wilayah pantai utara Kabupaten Manokwari. Dengan demikian diharapkan dapat digunakan sebagai informasi bagi peneliti lanjutan yang akan melakukan penelitian di Kampung Asai, dan sekitar serta dapat menjadi penyumbang ilmu pengetahuan terutama di bidang keanekaraman hayati bidang Mamalia.

\section{METODE PENELITIAN}

\section{Deskripsi Penelitian}

Penelitian ini dilaksanakan di Kawasan hutan Kampung Asai, wilayah pantai utara Kabupaten Manokwari yang berlangsung selama satu minggu yang dimulai dari tanggal 7 hingga 14 November tahun 2015. Dalam penelitian ini digunakan metode deskriptif dengan teknik jelajah. Variabel yang digunakan dalam penelitian ini terbagi menjadi dua yakni variabel utama dan variabel penunjang. Variabel utama yang di amati meliputi: karakteristik morfologi seperti: pola warna, kepala, ventral (belakang), dorsal (perut), sayap serta jenis kelamin. Selanjutnya morfometrik yang harus dicatat meliputi: panjang tubuh total (head and body [mm]), bobot badan (weight [gr]), panjang lengan bawah sayap (forearm $[\mathrm{mm}]$ ), panjang telinga (ear $[\mathrm{mm}]$ ), dan panjang ekor (tail $[\mathrm{cm}]$ ). Sedangkan untuk variabel penunjang, yaitu suhu dan kelembaban dan deskripsi/tipe habitat.

\section{Proses Pengumpulan Data}

\section{Persiapan Survei}

Kegiatan yang dilakukan sebelum survei adalah antara lain:

1. Persiapan awal yang dilakukan sebelum melakukan pengamatan yaitu melakukan survei lokasi dan habitat kelelawar pada siang hari.

2. Tentukan lokasi penempatan misnet (jaring kabut). Misnet di pasang pada lokasi yang diduga sebagai tempat 
beraktifitasnya kelelawar pada malam hari. Jaring kabut yang dipasang pada waktu senja hari pada pukul 17.00 18.00 WIT, dan untuk waktu pengamat dilakukan pada pukul 19.00 hingga pukul 22.00.

3. Kelelawar yang tertangkap pada misnet, langsung diambil dan catat waktu perjumpaan serta jenis kelamin, dan dimasukan kedalam kantung spesimen.

4. Untuk mengambil data suhu dan kelembaban, dilakukan dua kali pada saat pengamatan yaitu pada jam 19.00 dan 22.00.

\section{Pemasangan jaring kabut (Mist Net)}

Jaring kabut dipasang sepanjang jalur lokasi pengambilan data, yaitu pada daerah yang diduga menjadi lintasan kelelawar seperti tepi hutan atau pintu hutan, melintang sungai, perbukitan dan daerah terbuka. Pemasangan jaring dilakukan dengan mempertimbangkan beberapa faktor antara lain: jalur setapak atau dekat pohon yang sedang berbuah dan berbunga dengan memperhatikan tutupan kanopi, di atas sungai atau daerah ekoton. Jaring kabut dipasang sore hari sebelum matahari terbenam, untuk menghindari supaya tidak ada burung yang terperangkap dan kelelawar tidak bisa mendeteksi adanya jaring kabut yang dipasang. Agar tidak robek ketika ada kelelawar yang terjerat, maka jaring kabut harus dijaga atau diawasi dari tempat yang agak jauh. Ada dua cara memasang jaring kabut, yaitu:

1. Memakai tiang. Jaring kabut dipasang pada tiang bambu pada jarak 0,5 - 3 meter di atas permukaan tanah.

2. Cara gantung. Jaring dipasang pada tiang bambu atau digantung di atas ranting pohon dengan jarak $3-15$ meter di atas permukaan tanah.

Jaring kabut ini sebaiknya ditutup (digulung) pada siang hari untuk menghindari burung dan satwa lain terjebak dalam perangkap.

\section{Pembuatan Sampel Pengawetan Contoh dan Pemberian Label}

Pengawetan contoh dilakukan untuk keperluan identifikasi lebih lanjut atau koleksi spesimen. Tahapan dalam pengawetan contoh kelelawar adalah sebagai berikut:

1. Bius dengan menggunakan kloroform.

2. Timbang dan ukur dengan menggunakan jangka sorong bagianbagian tubuh untuk keperluan identifikasi antara lain: panjang tubuh total, panjang lengan bawah, panjang ekor, panjang telinga dan panjang kaki.

3. Beri label pada tiap spesimen yang berisi keterangan meliputi: (1) kode jenis, (2) tanggal ditemukan, (3) lokasi, dan (4) kolektor. Keterangan pada label ditulis dengan pensil, agar tidak larut dalam alkohol.

4. Suntikkan formalin 4 - $7 \%$ ke bagian tubuh kelelawar. Selanjutnya, awetkan dengan merendam spesimen ke dalam alkohol 70\% selama minimal 24 jam, atau hingga dilakukan identifikasi lebih lanjut.

\section{Analisis Data}

Data yang di peroleh dari penelitian ini, akan dianalisis secara deskriptif dan disajikan dalam bentuk tabel dan gambar. 


\section{HASIL DAN PEMBAHASAN}

\section{Jenis-jenis Kelelawar Pemakan Buah di Kampung Asai}

Berdasarkan hasil penelitian yang dilakukan, terdapat tiga jenis kelelawar pemakan buah yang terdiri dari satu famili yaitu famili Pteropodidae yang selanjutnya dideskripsikan pada Table 1 . Pada tabel di atas terlihat bahwa dari ketiga jenis kelelawar yang di jumpai yaitu: Rousettus amplexicaudatus merupakan jenis dengan jumlah individu terbanyak di bandingkan kedua jenis lainnya. Tingginya jumlah individu jenis ini di duga karena memiliki populasi yang sangat besar serta kemampuan beradaptasi yang cukup baik terhadap lingkungan.

Tabel.1 Jenis kelelawar di sekitar Kampung Asai.

\begin{tabular}{|c|c|c|c|c|c|c|}
\hline \multirow[t]{2}{*}{ Ordo } & \multirow[t]{2}{*}{ Famili } & \multirow[t]{2}{*}{ Spesies } & \multicolumn{3}{|c|}{$\begin{array}{c}\sum \text { individu berdasarkan tipe } \\
\text { habitat }\end{array}$} & \multirow[t]{2}{*}{$\sum$} \\
\hline & & & $\begin{array}{l}\text { Hutan } \\
\text { pantai }\end{array}$ & $\begin{array}{c}\text { Hutan } \\
\text { sekunder }\end{array}$ & $\begin{array}{l}\text { Hutan } \\
\text { primer }\end{array}$ & \\
\hline \multirow[t]{4}{*}{ Chiroptera } & Pteropodidae & Nyctimene albiventer & - & - & 2 & 2 \\
\hline & & $\begin{array}{l}\text { Rousettus } \\
\text { amplexicaudatus }\end{array}$ & 1 & 9 & 1 & 11 \\
\hline & & Macroglossus minimus & 1 & - & 3 & 4 \\
\hline & & $\sum$ total & & & & 17 \\
\hline
\end{tabular}

\section{Karakteristik Morfologi dari Jenis Kelelawar Pemakan Buah Yang Dijumpai}

\section{Nictymene albiventer}

Berikut ini merupakan bentuk morfologi dan morfometrik dari jenis kelelawar. Nictymene albiventer atau paniki adalah jenis kelelawar pemakan buah berukuran kecil yang memiliki buluh-buluh halus berwarna cokelat muda. Pada bagian dorsal berwarna cokelat keabu-abuan dan terdapat sebuah garis hitam, pada bagian ventral cokelat kekuningan, kedua bentuk warna tersebut pada bagian sayap berwarna cokelat dan terdapat bintik hitam dan putih, dan pada bagian telinga juga terdapat bintik putih. Adapun ukuran tubuh dari jenis ini memiliki ukuran berat badan 27 gr, panjang kepala $2,8 \mathrm{~cm}$, panjang lengan
2,7 cm, lebar lengan sayap 5,3 cm, panjang kaki belakang $3,5 \mathrm{~cm}$, panjang telinga $1, \mathrm{~cm}$, panjang betis $2, \mathrm{~cm}$, panjang ekor $1,9 \mathrm{~cm}$ jenis kelamin betina. Jenis ini dijumpai pada hutan primer.

Menurut Kartikasari dkk. (2012), jenis paniki merupakan kelelawar pemakan buah tetapi juga pemakan serangga. Selain itu juga jenis ini memiliki penyebaran yang secara luas tersebar di Filipina, Sulawesi dan Nusa Tengga, marga dari jenis ini paling beragam di Nugini, di mana tiga sampai empat jenis umumnya terdapat bersama - sama.

\section{Rousettus amplexicaudatus}

Karakteristik morfologi dan morfometrik Rousettus amplexiaudatus jenis ini memiliki warna buluh rambut pada bagian dorsal warna buluh atau rambut hitam kecokelatan sedangkan 
pada bagian ventral kekuningan selain itu ukuran berat berat badan 83 gr panjang kepala $3,7 \mathrm{~cm}$, panjang lengan $2,4 \mathrm{~cm}$, lebar lengan sayap 7, cm, panjang kaki belakang $6,5 \mathrm{~cm}$, panjang telinga 1,5 $\mathrm{cm}$, panjang ekor $1,1 \mathrm{~cm}$ panjang betis $2,3 \mathrm{~cm}$, jenis kelamin betina.

Jenis ini umumnya merupakan jenis yang mampu beradaptasi dengan di

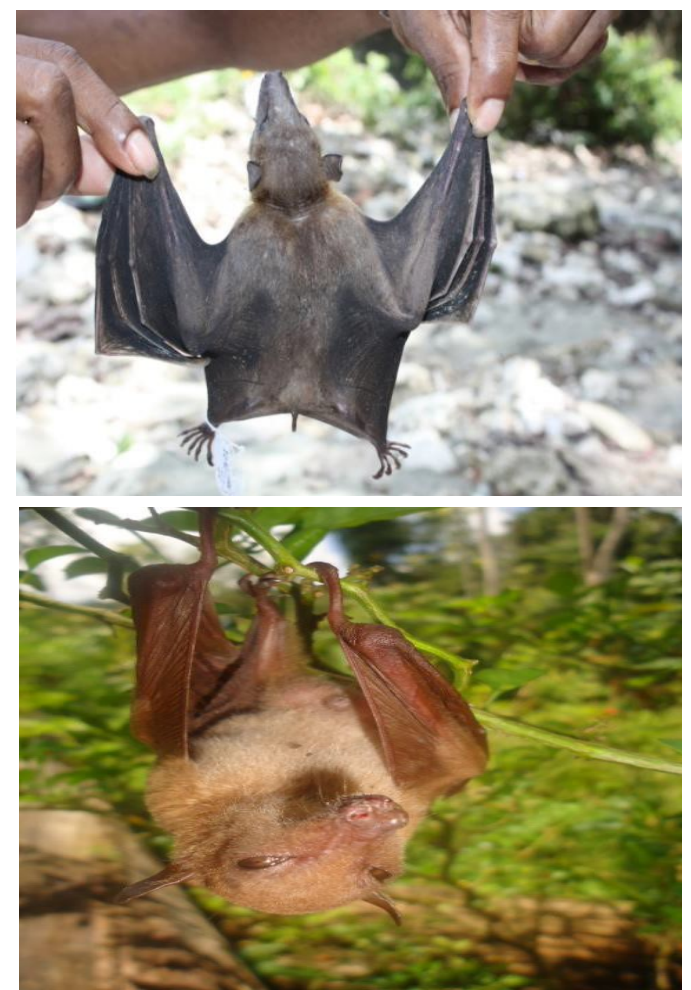

berbagai habitat termasuk di hutan primer dan sekunder dan habitat yang lebih rendah seperti kebun-kebun dan lingkungan pedesaan (Kartikasari dkk. 2012). Pernyataan tersebut sama halnya dengan jenis yang dijumpai pada saat pengamatan yang mana jenis tersebut dijumpai pada kebun warga dan berdekatan dengan pemukiman warga.

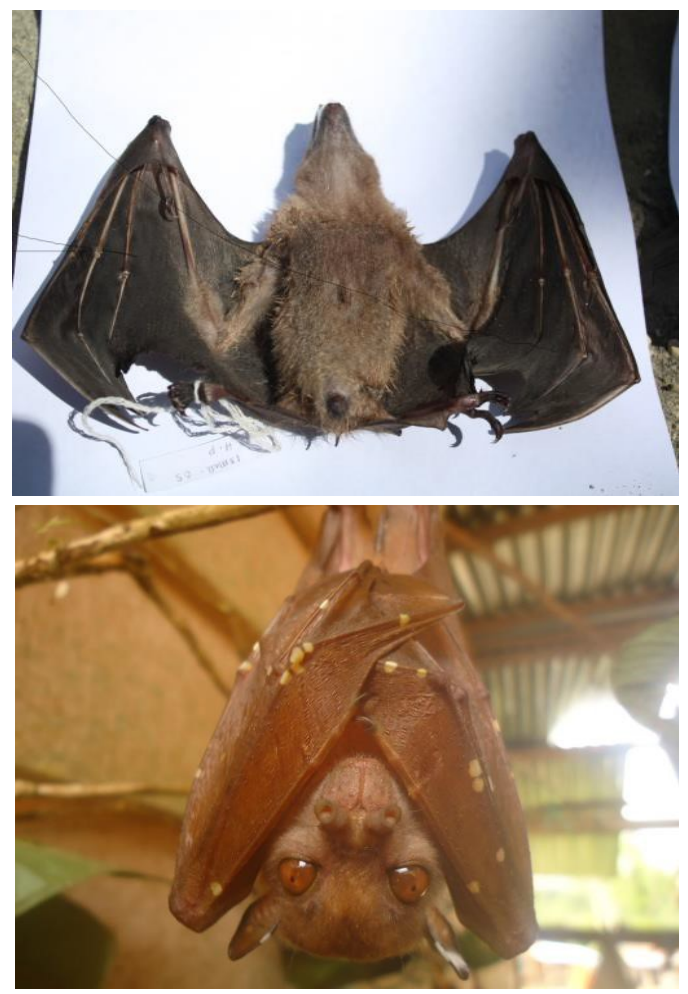

Gambar 1. Jenis kelelawar yang ditemukan di sekitar Kampung Asai. Gambar atas merupakan jenis Rousettus amplexicaudatus pada posisi tampak depan dan belakang; gambar bawah sisi kiri merupakan jenis Macroglossus minimus; gambar bawah sisi kanan merupakan jenis Nyctimene albiventer.

Jenis ini umumnya merupakan jenis yang mampu beradaptasi di berbagai habitat termasuk di hutan primer dan sekunder dan habitat yang lebih rendah seperti kebun-kebun dan lingkungan pedesaan (Kartikasari dkk. 2012). Pernyataan tersebut sama halnya dengan jenis yang dijumpai pada saat pengamatan yang mana jenis tersebut dijumpai pada kebun warga dan berdekatan dengan pemukiman masyarakat. Menurut Suyanto (2001), jenis ini biasanya memiliki habitat seperti, bertenker di dalam gua, kadang dalam kegelapan total, 
memakan buah-buahan nectar dan tepung sari, jenis ini diperkirakan mampu terbang mencari makan sejauh 40-50 km dalam semalam.

Jenis Rousettus amplexicaudatus memiliki daerah mencari makan daerah atau wilayah jelajah mulai dari hutan primer daratan sampai hutan pantai. Menurut (Suyanto 2001) jenis Rousettus amplexcaudatus penyebaranya meliputi Myanmar Selatan, Thailand, Kamboja, Vietnam, Semenanjung Malaysia, Filipina, Indonesia sampai Papua Nugini, dan Kepulauan Salomon.

Jenis ini memiliki sumber pakan seperti jenis. Ficus septica, Ficus spl, Horsfierdia irya, Macaraga mappa, Carica papaya. Yustian (2012) menyatakan pakan kelelawar meliputi, $T$. bellirica, T. cattapa, Syzygium spp., Nephelium spp., Strombosia javanica, Mangifera sp., Ficus hispida, Ficus sp.1, Ficus sp.2, Piper aduncum, Solanum sp., Achras zapota, Psidium guajava, Erithryna indica. dan Ceiba petandra. Selain jenis buah tersebut kemungkinan besar ada jenis lain yang menjadi pakan kelelawar, sesuai dengan sifat oputunis pada kelelawar yang akan memilih pakan apapun yang terdapat di area jelajahnya (Nowak 1994).

\section{Macroglossus minimus}

Karakteristik morfologi Macroglossus minimus adalah jenis pemakan buah yang berukuran kecil yang memiliki kuku (cakar) pada jari sayapnya yang kedua; sedangkan dari Syconycteris berdasarkan membrane antar paha yang cukup lebar, dan adanya celah gigi seri tengah yang renggang. Pada bagian dorsal berwarna cokelat dan putih pada bagian ventral dan kekuningan selain itu ukuran berat badan 13 gram, panjang kepala $2,4 \mathrm{~cm}$, panjang lengan $1,6 \mathrm{~cm}$, lebar lengan sayap $3,9 \mathrm{~cm}$, panjang kaki belakang 2,3 cm, panjang telinga $1 \mathrm{~cm}$ panjang betis $1,4 \mathrm{~cm}$. Macroglossus minimus adalah sejenis kelelawar pemakan buah nectar dari Macroglossus minimus suku Pteropodidae (kerabat codot), dinamai demikian karena codot ini sering terlihat hinggap di jantung pisang untuk menghisap nektarnya. Vegetasi seperti jenis Ficus punguens, Ficus benjamina, Pometia piñata, Artocarpus altilis, Pandanus sp, Syzygium malacensis, Syzygium sp1, Ficus septic, Ficus sp, Mangivera sp, Musa sp, Artorcapus altlis, dan Macanaga.

\section{DAFATAR PUSTAKA}

Flannery. 1995. Mammals of New Guinea. Australian Museum.Revised and Updated Edition.

Kartikasari SN, Marshall AJ dan Beehler BM. 2012 Ekologi Papua, Seri Ekologi Indonesia, Jilid VI.

Nowak L. 1994. Walker's mammals of the World, Vol. I. John Hopkins University Press, Baltimore and London.

Santosa Y, Ramadhan EP dan Rahman DA. 2008. Studi keanekaragaman mamalia pada beberapa tipe habitat di Stasiun Penelitian Pondok Ambung, Taman Nasional Tanjung Puting Kalimantan Tengah. Media Konservasi Vol. 13, No. 3 Desember 2008: 1 - 7.

Suyanto A. 2001.Kelelawar di Indonesia (LIPI- Seri Panduan Lapangan). Pusat Penelitian dan Pengembangan Biologi, LIPI. Bogor. Indonesia.

Yustian K. 2012. Kajian pakan kelelawar pemakan buah (Megachiroptera) di taman nasional Bukit Barisan Selatan dan Perkebunan di sekitar. Universitas Lampung. 